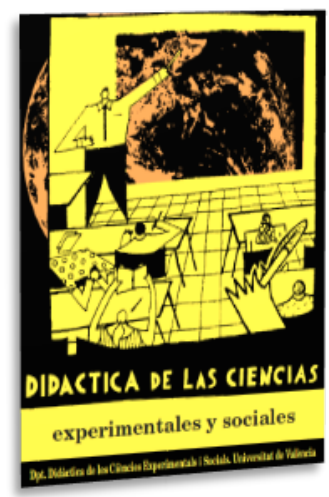

\title{
Hereros y Namas: el comienzo de los genocidios en el siglo XX. Análisis desde la perspectiva de la geografía de la memoria
}

\author{
Hereros and Namas: the beginning of the \\ genocides in the 20th century. Analysis from the \\ perspective of the geography of memory
}

DOI: $10.7203 / D C E S .41 .21491$

\author{
María Cristina Nin \\ Universidad Nacional de La Pampa (Argentina), ninmcristina@gmail.com \\ ORCID iD: https://orcid.org/0000-0002-7707-4302
}

\begin{abstract}
RESUMEN: En el presente artículo se sistematiza el proceso genocida que sufrieron los pueblos Hereros y Namas en África Sudoccidental a principios del siglo XX. El principal propósito es el de generar el intercambio y debate tanto en el ámbito de la investigación como en el educativo. La perspectiva geohistórica de los procesos de construcción territorial contribuye a comprender el presente en relación al pasado. A partir de metodología interpretativa, fuentes secundarias y el genocidio como categoría conceptual, se deconstruye la compleja trama territorial marcada por violencias. Se concluye que la memoria es una construcción colectiva y que, junto a los otros cuatro pilares de la justicia transicional: la verdad, la justicia, la reparación y las garantías de no repetición, depende que en el futuro se construyan sociedades y territorios con convivencia pacífica.
\end{abstract}

Palabras ClaVe: genocidio, Geografía, memoria, colonización, Hereros, Namas

ABSTRACT: This article systematizes the genocidal process suffered by the Herero and Nama peoples in South West Africa at the beginning of the 20th century. The main purpose is to generate exchange and debate both in the field of research and education. The geohistorical perspective of the processes of territorial construction contributes to understanding the present in relation to the past. Based on interpretative methodology, secondary sources and genocide as a conceptual category, the complex territorial framework marked by violence is deconstructed. It is concluded that memory is a collective construction and that, together with the other four pillars of transitional justice: truth, justice, reparation and guarantees of non-repetition, depends on the future construction of societies and territories with peaceful coexistence.

KEYWORDS: genocide, Geography, memory, colonization, Herero, Nama

Fecha de recepción: mayo de 2021 Fecha de aceptación: noviembre de 2021

Este artículo es una versión ampliada y revisada de un capítulo de la tesis de Doctorado en Geografía titulada "Geografía y genocidios: aportes de la geografía a la enseñanza de procesos traumáticos y el ejercicio de la memoria" defendida en noviembre de 2020 en la Universidad Nacional del Sur, Argentina. La autora es Profesora Asociada de Didáctica Especial de la Geografía en el Departamento de Geografía e Investigadora en el Instituto de Geografía de la Facultad de Ciencias Humanas, Universidad Nacional de La Pampa (UNLPam) Argentina. 
El real drama del destino humano, de los seres humanos frente a su propia muerte, volvió a escena en el siglo XX y está volviendo a escena hoy; un drama que es aún más incomprensible en situaciones de muerte masiva, de muerte no visibilizada, cuando se trata de un asesinato a gran escala. Las exhumaciones, como manifestaciones de una voluntad de aprender, también de un deseo de ver y entender, parecen representar, en este sentido, una de las muchas respuestas de la sociedad al misterio de la muerte violenta masiva (Garibian, Anstett y Dreyfus, 2017, p. 20).

\section{INTRODUCCIÓN}

En 1884, la Conferencia de Berlín reunió a trece países europeos con el fin de organizar el reparto de África, hecho que marcó la etapa del nuevo imperialismo o colonialismo europeo. Sin embargo, Kabunda Badi (2016) sostiene que dicho reparto comenzó años antes de la Conferencia y se extendió hasta la Primera Guerra Mundial. Las fronteras africanas han sido trazadas por potencias extraafricanas, desconociendo las realidades humanas, socioculturales, medioambientales o geográficas locales. "En Berlín, donde África fue por primera vez el tema de una conferencia internacional, sorprende la ausencia de los africanos en dicho acontecimiento histórico" (Kabunda Badi, 2016, p 10).

La industria alemana en crecimiento requería de materias primas y mercados donde colocar sus productos y realizar inversiones. En este contexto de expansión económica, Alemania se interesa por África y decide crear un imperio colonial incorporándose al reparto de este continente. El proyecto imperialista y colonialista se sustentó en ideas teóricas de la época. Friedrich Ratzel, geógrafo representante de las ideas del determinismo ambiental, planteó la teoría del espacio vital o Lebensraum que sirvió de justificación para el avance del imperialismo. Su teoría establecía la relación entre espacio y población, asegurando que la existencia de un Estado quedaba garantizada cuando dispusiera del suficiente espacio para atender a las necesidades de la misma. Más tarde fue retomada por el nazismo.

El territorio de África Sudoccidental estuvo ocupado por los grupos étnicos los san (bosquimanos) y khoikhoi; al norte por los ovambo y los herero de lengua bantú. Más tarde el pueblo nama, conocido como la "Nación Roja", se instaló en el territorio sureño y vivió de la cría de ganado, se organizaban en clanes. Las primeras incursiones europeas en este territorio datan del año 1670, cuando misioneros alemanes, comerciantes y balleneros noruegos llegaron a la costa y algunos avanzaron tierra adentro. En 1870, los británicos se instalaron en Walvis Bay, y en 1883 un comerciante alemán, Adolf Lüderitz, compró la Bahía de Angra Pequeña ubicada entre Walvis Bay y el Río Orange. Bismarck proclamó el Protectorado sobre dicho territorio (actual Namibia) y, de este modo, los alemanes obtuvieron el acceso a la cuenca del Zambeze. Primero fue una sociedad privada la que se hace cargo del territorio y 1892 se convierte en colonia alemana (Sellier, 2005).

En la Figura 1, que muestra el reparto de África en 1914, se puede apreciar la ubicación de los territorios alemanes y, en particular, el sudoeste africano donde se desarrollará el proceso genocida de los Hereros y Namas. Alemania ocupó y gobernó los territorios de Camerún alemán que formaban los actuales países de República Centroafricana, Chad, Gabón, Nigeria, Congo y Camerún, partes de Togo y Ghana; África Oriental alemana formada por Tanzania y partes de Ruanda y Burundi y África del Sudoeste, la actual Namibia. Su política colonial, hasta que fue derrotada en la Primera Guerra Mundial, fue agresiva y respondía a las órdenes del Kaiser Guillermo II. 
FIGURA 1. El reparto de África

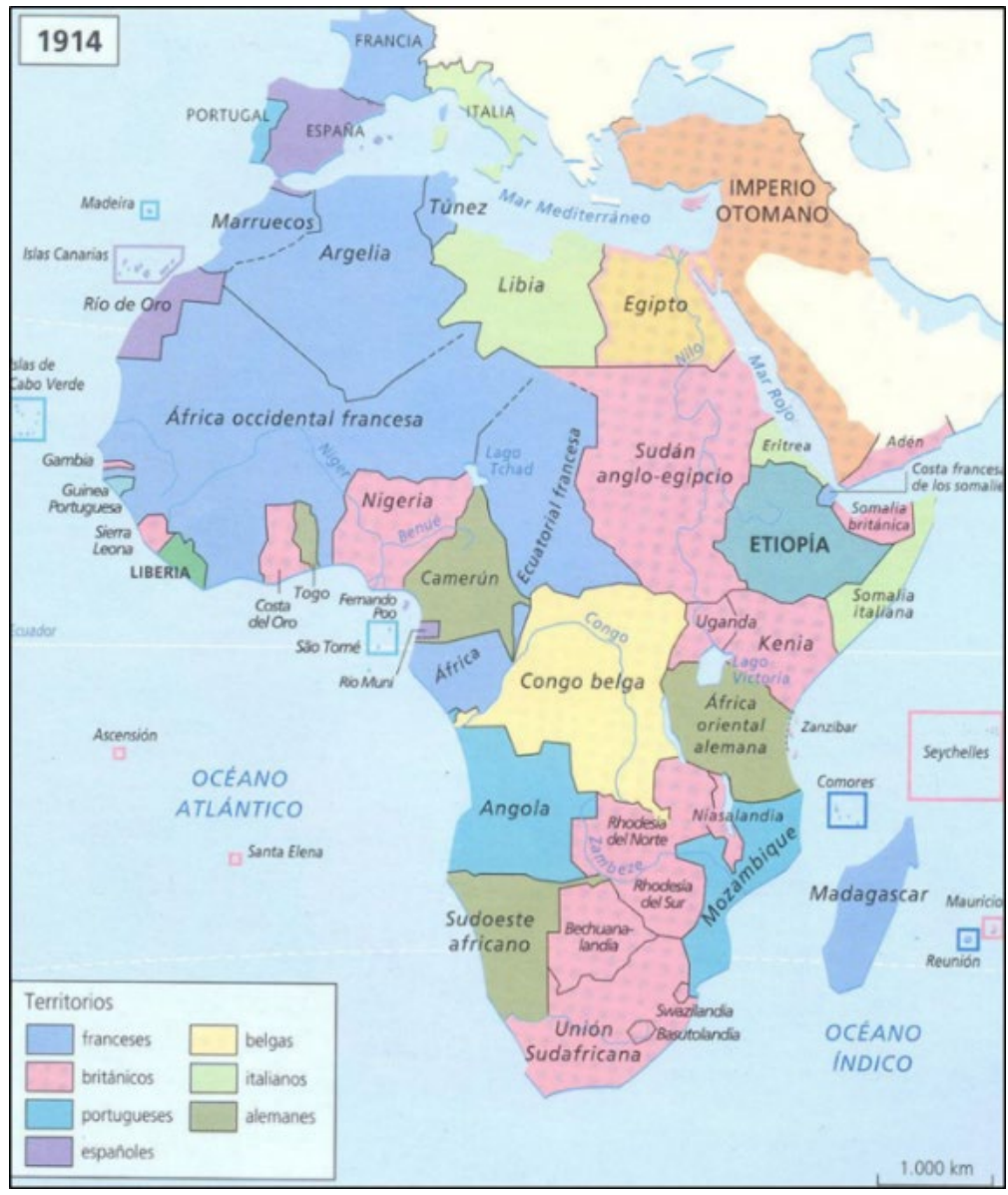

Fuente: Sellier, 2005, p. 26

La organización de la colonia alemana se basó en la confiscación de tierras al pueblo herero para beneficiar a los colonos alemanes, Ante este desequilibrio económico y avasallamiento de propiedades los herero se rebelaron en 1904. "Al igual que en los casos británico y francés, detrás de la fundación del imperio colonial alemán estaba la actividad de sociedades colonialistas, como la Unión Colonial Alemana (1882), la Sociedad para la Colonización Alemana (1884) y la Liga Pangermana (1891)" (Ceamanos, 2016, p.48). El territorio de África del Sudoeste fue colonia alemana entre 1884 y $1915^{1}$. Los colonos alemanes construyeron vías de ferrocarril desde Swakopmund y Lüderitz. El territorio adquirió valor estratégico con el descubrimiento de ricos yacimientos de hierro, plomo, cobre y diamantes, a los que luego se agregó el hallazgo de metales de interés militar: manganeso, tungsteno, vanadio, cadmio y grandes cantidades de uranio.

En ese contexto se desarrolló lo que se puede identificar como el primer genocidio del siglo $\mathrm{XX}$, aunque escasamente investigado y públicamente conocido. En este artículo se sistematiza dicho proceso con el propósito de generar debates tanto en el ámbito de la investigación como en el educativo. La perspectiva geohistórica de los procesos de construcción territorial contribuye a comprender el presente en relación a al pasado. Los reclamos de reconocimiento que se suceden en la actualidad tienen su anclaje en el trauma y las heridas que estos pueblos aún tienen marcados y en las reivindicaciones por la construcción de memoria que otros grupos afectados a lo largo del siglo $\mathrm{XX}$ y en diferentes latitudes consolidaron.

\footnotetext{
${ }^{1}$ En 1915, Sudáfrica, como miembro del Commonwealth británico, ocupó la colonia alemana de África del Sudoeste y gobernó Namibia entre 1915 y 1966. Namibia luchó por independizarse de Sudáfrica durante el periodo que va de 1966 a 1990. Finalmente, Namibia proclamó la independencia en 1990.
} 
La geografía como ciencia social, contribuye a la construcción de ciudadanía. Sus herramientas teóricas y metodológicas brindan posibilidades para relacionar el pasado, el presente y la planificación el futuro, con conciencia histórica y geográfica. Es decir para defender los principios de justicia social y económica, así como la protección de los derechos humanos, la igualdad de oportunidades, la inclusión de sectores marginados, el respeto y cuidado del ambiente, la construcción de memora colectiva. En síntesis, la ciencia geográfica aporta a la formación de cultura democrática.

\section{Metodología}

La metodología utilizada para el desarrollo de esta investigación es cualitativa interpretativa. Desde esta perspectiva se pretende, elaborar una reflexión crítica que contribuya a generar conocimiento que tenga utilidad para la enseñanza de procesos geohistóricos complejos. La metodología cualitativa enriquece y sirve de fundamento a las nuevas perspectivas de la ciencia geográfica. Es desde la Geografía social, que se pretende comprender los fenómenos sociales, desde la perspectiva de los actores o sujetos que participan de ellos. Hérin (2006, p.1) expresa respecto a la Geografía social francesa que, "Inmersa en el mundo que vivimos, pretende ser a la vez científica e implicada en las cuestiones de la sociedad de nuestro tiempo. También es crítica tanto en el terreno científico como en el campo social".

La investigación en geografía social se sustenta en una actitud social crítica y en los principios universales de la racionalidad en la investigación y en valores universales que según Hérin (2006, p. 28) deberían "regular las relaciones sociales: el respeto al ser humano; la igualdad de derechos, de deberes y de oportunidades, de donde proceden los principios de justicia y equidad; el respeto a las libertades individuales y colectivas (...); los principios de solidaridad". Es desde esta perspectiva geográfica que se pretende contemplar las dimensiones que conforman las relaciones sociales en territorios en conflicto para contribuir al conocimiento de las relaciones de alteridad.

Una de las estrategias que se emplean en la presente investigación es la de estudios de casos. A partir de ellos se puede focalizar en diversas variables que los componen, posibilitar el abordaje en profundidad y su comprensión, así como también permiten la comparación con otros casos ocurridos en momentos históricos diferentes.

El caso seleccionado se corresponde con la categoría de estudios de caso instrumentales. El propósito de la presentación de los mismos es demostrar la importancia de conocer y comprender genocidios históricos y actuales, para reflexionar acerca de la enseñanza de procesos traumáticos para la formación de ciudadanos respetuosos de los derechos humanos. El caso del genocidio de los Hereros y Namas contiene descripciones ricas y densas reconstruidas a partir de la consulta de múltiples fuentes. Además, presenta una perspectiva integradora, tal como lo define Yin, un estudio de caso "(...) estudia un fenómeno contemporáneo dentro de un contexto de vida real especialmente cuando los límites entre el fenómeno y su contexto no son claramente evidentes" (Yin, 1994, p. 13).

Los estudios de caso como metodología de investigación también pueden ser utilizados como estrategia didáctica. Desde la perspectiva educativa, se constituye en un proceso didáctico "(...) que intenta la descripción, análisis e interpretación de un objeto de estudio histórico concreto y singular en términos de calidad y complejidad" (Prats, 2001, p. 54).

La Geografía, como ciencia social tiene como propósito explicar el mundo, por lo tanto la búsqueda de causalidades y explicaciones son sus objetivos principales. Por otra parte, y tal como afirma Perry (1998), los estudios de caso como estrategia de investigación operan dentro del paradigma del realismo, es decir incorporan teorías existentes, construyen nuevas, en síntesis, presentan una mezcla de deducción e inducción. "Los casos nos ayudan a conocer pero también constituyen en sí mismos conocimiento. Casos bien seleccionados o construidos nos permiten tratar temas que por su complejidad difícilmente nos atrevíamos a abordar" (Litwin, 2008, p. 94). A través del estudio de caso seleccionado es posible fortalecer y desarrollar científicamente las temáticas vinculadas con la enseñanza de procesos traumáticos. 
Se utilizan, como toda investigación social, variedad de materiales documentales, MacDonald y Tipton (1993) citado en Valles (2000) definen a los documentos como cosas que podemos leer y que se refieren al mundo social. Tales como informes oficiales, registros privados y personales como cartas, diarios y fotografías. En relación al uso de la prensa como documentos de consulta para el desarrollo de la investigación, se toma la idea de Duverger (1981) quien expone que puede ser fuente de documentación sobre los hechos que se indagan debido a que los periódicos brindan información que aún no se encuentra en los archivos. Es decir, son acontecimientos del presente que conforman la trama explicativa del problema a investigar, se presentan en la prensa en la modalidad de reportajes, notas de opinión, fotorreportajes, suplementos, entre otros. No obstante, la relevancia de la información que se pueda utilizar, este tipo de documentos presenta problemas, tales como si se reflejan correctamente los hechos o el modo en que cada periódico da a conocer la noticia. Esta es una de las razones por las que este tipo de documentos es complementario o se utiliza para triangular con otros, tales como datos o documentos oficiales, en este sentido Ruiz Olabuenaga expresa, "Sus objetivos son el enriquecimiento (por medio de la apertura a las vías de información y a los modos de interpretación) y el control de calidad (por medio del contraste entre informaciones e interpretaciones coincidentes lo mismo que discordantes) (Ruiz Olabuenaga, 1996, p.113). En las investigaciones geográficas, así como en otras disciplinas, la triangulación entre la diversidad datos de la realidad social, y el análisis de contenido de diferentes documentos, contribuyen a otorgar fiabilidad y fortaleza a las investigaciones cualitativas. Para la realización del presente trabajo se consultaron investigaciones académicas, artículos periodísticos de diferentes fuentes, páginas web de UNESCO, ONU, museos entre otras.

\section{RESULTADOS}

\subsection{El concepto de genocidio como categoría de interpretación en clave territorial}

Los actores a través de sus acciones realizan transformaciones en los territorios a partir de las cuales se modifican las redes de relaciones multiescalares y las organizaciones y culturas locales. Los actores son productores de territorio, en forma material y simbólica. Sin embargo, cuando esta producción espacial se ve alterada por agentes externos con intereses contrapuestos a la sociedad local, se producen procesos violentos que destruyen la trama territorial. Una de las causas del inicio de procesos genocidas es no aceptar al "otro" como diferente, es rechazar la otredad. En la construcción de la alteridad, la espacialidad cumple un rol destacado y por lo tanto, la Geografía brinda herramientas para comprenderla. En esta línea de investigaciones se basa el enfoque postcolonial como intento de descolonizar la mente del etnocentrismo y del eurocentrismo (Albet y Benejam, 2000).

La ruptura de las territorialidades construidas socialmente es una de las consecuencias de los genocidios y habilita el estudio en clave territorial. El concepto genocidio involucra, tal como Lemkin propuso, “( ...) baterías de poderes coercitivos: legales, administrativos, políticos, ideológicos y económicos tanto como armados, violentos y militares" (Shaw, 2013, p. 61-62). Además de violencia física, el objetivo es destruir la trama social y cultural de un determinado grupo. "Una postura común es considerar al genocidio como una forma extrema de conflicto entre grupos sociales, particularmente grupos étnicos" (Shaw, 2013, p. 179). Los genocidios están impregnados de conflictos intergrupales, de este modo el conflicto se convierte en funcional al plan de exterminio.

Los procesos genocidas están marcados por violencia y exterminio con la intención de destruir un grupo social. Semelín (2002) define las violencias extremas como las acciones específicas que exceden la violencia y son inaceptables para la concepción de humanidad de la modernidad. Caracterizadas por la variable cualitativa (atrocidades acompañadas de actos de violencia crueles) y cuantitativa (destrucción masiva de poblaciones civiles que no están implicadas en el conflicto). Los genocidios destruyen la trama territorial de un grupo social y por lo tanto, los desplaza de su lugar de 
pertenencia, es decir de su patria. Uno de los rasgos distintivos de los genocidios es la expulsión de las poblaciones de su lugar de residencia, por lo tanto el genocidio siempre implica el desplazamiento territorial. Tanto el exterminio como el desplazamiento son armas de destrucción del grupo y de su trama social. "Los genocidas generalmente apuntan tanto a destruir el poder de los grupos meta dentro de un territorio dado como a expulsar o quitarlos de ese territorio, ya sea simultánea o secuencialmente" (Shaw, 2013, p. 105). Según este mismo autor, la Convención para la Prevención y la Sanción del Delito de Genocidio de las Naciones Unidas (UNCG) no se refería a la expulsión como componente del genocidio, en cambio, sí especificó los medios del genocidio en términos de destrucción física y biológica.

El término genocidio es controvertido para las ciencias sociales y presenta diversas connotaciones, las de la memoria, muchos son los grupos que desean que se reconozcan la matanza de sus integrantes en diferentes períodos históricos; las connotaciones vinculadas a la acción inmediata, cuando una población está en peligro y recurre a la intervención internacional para evitar las muertes, y las jurídicas como herramienta para demandar a los responsables (Semelín, 2002). Se podría pensar en connotaciones educativas cuando se propone en la Convención de 1948 la prevención de los genocidios y también geográficas, si se analizan los procesos genocidas como modificadores de la organización territorial.

Existen discusiones, de orden jurídico, político y sociológico respecto al concepto genocidio. A nivel jurídico y gracias a los aportes de Lemkin, el genocidio se constituye en una categoría jurídica, es a partir de la Segunda Guerra Mundial cuando comienza a circular como la definición de un nuevo tipo de delito. En 1948, cinco años después de que el concepto sea propuesto por Lemkin, comenzó a formar parte del derecho internacional. A partir de discusiones de orden político en las Naciones Unidas el concepto quedó limitado a la destrucción de determinados grupos: étnicos, nacional, racial y religioso. Las disputas por recursos y territorio han sido motivo de la planificación masiva de asesinatos con el fin de apoderarse de los bienes codiciados. Sin embargo, la novedad de la modernidad es que el concepto de genocidio “(...) surgió para diferenciar esa modalidad clásica de la decisión de organizar una campaña sistemática para eliminar a grupos enteros de población, con el objetivo de erradicarlos del planeta y/o de utilizar el terror para disciplinar al conjunto social (Feierstein, 2016, p.14).

Las violencias perpetradas en diferentes territorios en los que primó la desigualdad entre colonizadores y población autóctona, construyó "geografías del terror"2 (Oslender (2018), violencias que se convierten en cultura del miedo, la cual permite el control de las poblaciones que lo padecen. Entre las características que el autor define, se encuentran: la producción de paisajes del miedo, son la huella del uso continuo del terror en una región. Luego del ataque a poblaciones civiles, tales como incendios de campos, viviendas, bombardeos, las marcas visibles se constituyen en estampas de los agentes del terror a su vez son recuerdos de los actos violentos y futura amenaza para los pobladores atemorizados. Estos paisajes se leen a través de las huellas que transforman el espacio en paisajes del miedo y manifiestan el terror como espectáculo, como estrategia comunicativa. La movilidad y prácticas espaciales rutinarias restringidas, que son impuestas por determinados regímenes autoritarios. Las restricciones pueden ser explícitas e impuestas por los agentes de control que impiden el desplazamiento de la población o implícitas impuestas por el miedo a desplazarse a ciertos lugares donde se verían amenazados. Este contexto de terror invade de un sentimiento de inseguridad que modifica los hábitos cotidianos de la población y el espacio se fragmenta. Esto puede llevar a la creación de campos de confinamiento tales como guetos o campamentos de refugiados. La transformación dramática del sentido de lugar, la dimensión subjetiva del sentido de lugar, los

\footnotetext{
2 Oslender propone el marco conceptual de las Geografías del Terror en base a su investigación del caso Colombiano. Sin embargo, abre la posibilidad de aplicarlo a otros territorios y otras realidades violentas. Su propuesta es "(...) una agenda para abordar el terror como un conjunto complejo de espacios, emociones, prácticas, movimientos y materialidades en una gama de escalas desde el cuerpo hasta las microgeografías de la casa, la calle, el río, el bosque y la región" (Oslender, 2018, p. 83).
} 
sentimientos hacia el mismo se modifican en contextos de violencia. Las personas sienten, piensan y hablan de diferentes maneras sobre sus lugares de vida que fueron impregnados de experiencias traumáticas, recuerdos y temor. El silencio suele ser la reacción de las poblaciones afectadas y atemorizadas. La desterritorialización, se produce cuando el desplazamiento físico y forzado de comunidades es provocado por amenazas, masacres y ataques. Hay una pérdida del control territorial de la población local, poblaciones enteras huyen de la violencia, abandonan sus tierras, sus casas. También existe la desterritorialización mental que es cuando las personas pierden el control territorial, restringen sus movimientos habituales, modifican sus rutinas y evaden los lugares que eran su espacio de vida. Los movimientos fisicos en el espacio, el desplazamiento forzado es la reacción a situaciones de amenaza y matanzas. Estos movimientos de población, que suelen ser masivos resultan en migraciones de corta duración y distancia o bien de muy prolongados períodos. La reterritorialización, es parte del proceso de desterritorialización, el retorno de las poblaciones desplazadas a su lugar de origen es el fin de la solución del conflicto. Este proceso es largo, complejo e implica redefiniciones en las relaciones sociales y una reconstrucción de los paisajes del miedo en espacios de solidaridad y paz. Los que no regresan, emprenden procesos de reterritorialización en otros espacios, donde se gesta la construcción de nuevas identidades. Por último las estrategias espaciales de resistencia, brindadas por las posibilidades de movilizarse, de defenderse y de resistir a los actores violentos y confrontar al terror. La huida, el escape o el hecho de esconderse de los atacantes, pueden ser acciones de resistencia.

Así mismo, es posible aplicar en la comprensión de los procesos genocidas los rasgos aportados por Oslender (2018) en lo que denomina las geografías del terror, dado que todas son acciones de los individuos que se transforman en estrategias sociales territorializadas (Nin, 2020). Las resistencias emprendidas por los descendientes de los grupos afectados se manifiestan en los juicios, el reclamo por resarcimiento económico, la creación de sitios y monumentos de memoria, los proyectos de divulgación y enseñanza del genocidio, entre otras.

\subsection{El genocidio como estrategia de dominio colonial}

El territorio ocupado por Alemania se caracterizaba por la predominancia de mesetas ubicado en la franja del trópico de Capricornio surcada por el desierto de Namibia. Hacia el este se encuentra el desierto de Kalahari, el cual era habitado por grupos de pastores y cazadores. El pueblo Herero ${ }^{3}$ se dedicaba a la ganadería. El régimen de explotación económica del territorio se basó en la marginación jurídica, ocupación de tierras de los Herero a través de la actividad ganadera extensiva, actividad de la que quedaron relegados, para desarrollarla se apoderaron de su ganado. Estos fueron los motivos de una revuelta ocurrida en 1904, en la que miembros del pueblo herero, como estrategia de supervivencia y resistencia al régimen atacaron a los colonos. En respuesta a la rebelión que integrantes de ambas tribus habían iniciado, la política de ejecución comenzó en octubre de 1904 ordenada por el general Lothar Von Trotha, quien lo anunciaba de este modo;

El pueblo herero tendrá que dejar el país de lo contrario, lo forzaré a hacerlo por medio de las armas. Dentro de las Fronteras alemanas, todo herero, esté armado o desarmado, con o sin su ganado, será asesinado. No aceptaré mujeres o niños. Serán devueltos a su pueblo; de lo contrario, ordenaré que se los mate (Sarkin, 2004, p. 96).

En agosto de 1904 se produjo la batalla de Waterberg, la que provocó grandes pérdidas humanas para los Hereros. A los sobrevivientes se los empujó al desierto de Omaheke, al Kalahari con el

\footnotetext{
${ }^{3}$ El pueblo de Namibia está compuesto por varios grupos étnicos. En la actualidad se distribuyen de la siguiente manera: Ovambo (47,4\%), Kavango (8,8\%), Damara (7,1\%), Herero (7,1\%) y otros. Existe una minoría de origen europeo que representa $4,6 \%$ de la población.
} 
propósito de aislarlos y que mueran de sed y hambre (Figura 2). El pueblo Nama o Namaqua ${ }^{4}$ sufrió las mismas condiciones de explotación y también organizó la resistencia. Su destino fue el mismo que el de los Hereros. Los sobrevivientes, en su mayoría mujeres y niños, fueron confinados en campos de concentración y obligados a practicar trabajos forzados. Este proceso es considerado un genocidio ya que se asesinaron aproximadamente 65.000 integrantes de la etnia Herero (Bruneteau, 2009; Ceamanos, 2016).

FIGURA 2. Hereros sobrevivientes de hambrunas en el desierto

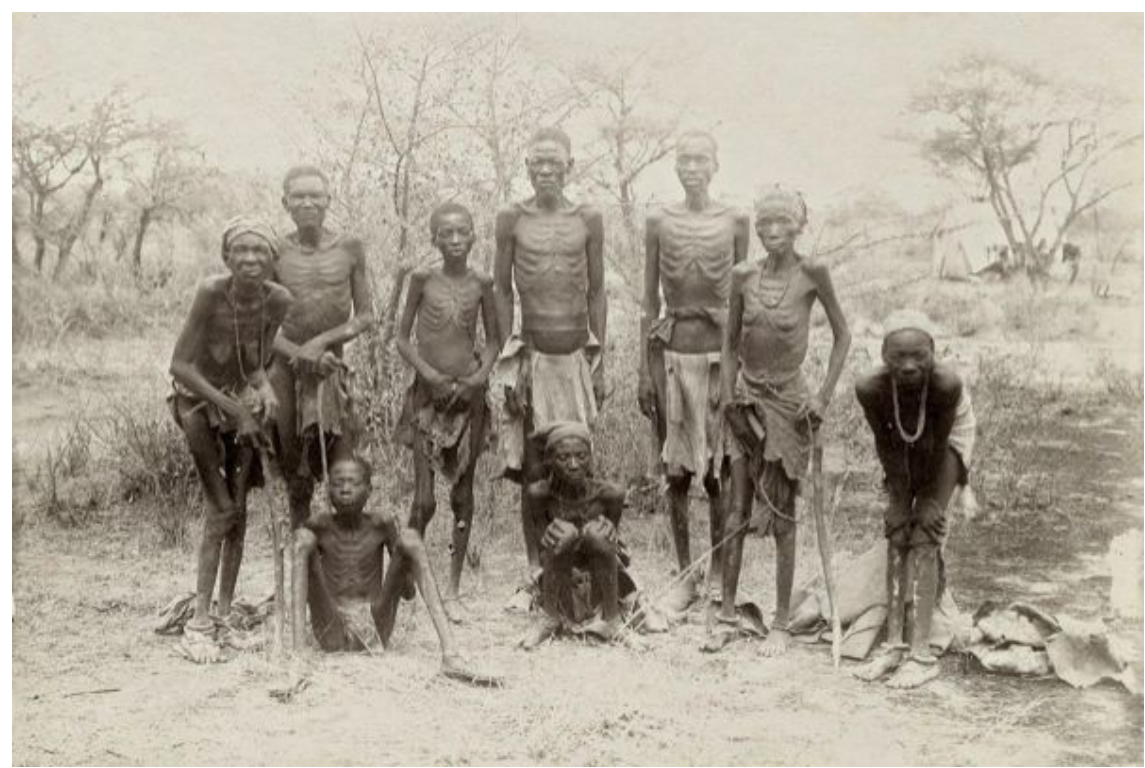

Fuente: Rojas, 2019

En territorio de la actual Namibia, ubicada en África sudoccidental (Figura 3), a comienzos del siglo XX, entre 1904 y 1908, y como parte de la estrategia imperialista alemana en este continente, se produjeron las matanzas de los Herero y los Nama, un genocidio invisibilizado.

FIGURA 3. Mapa histórico de Namibia

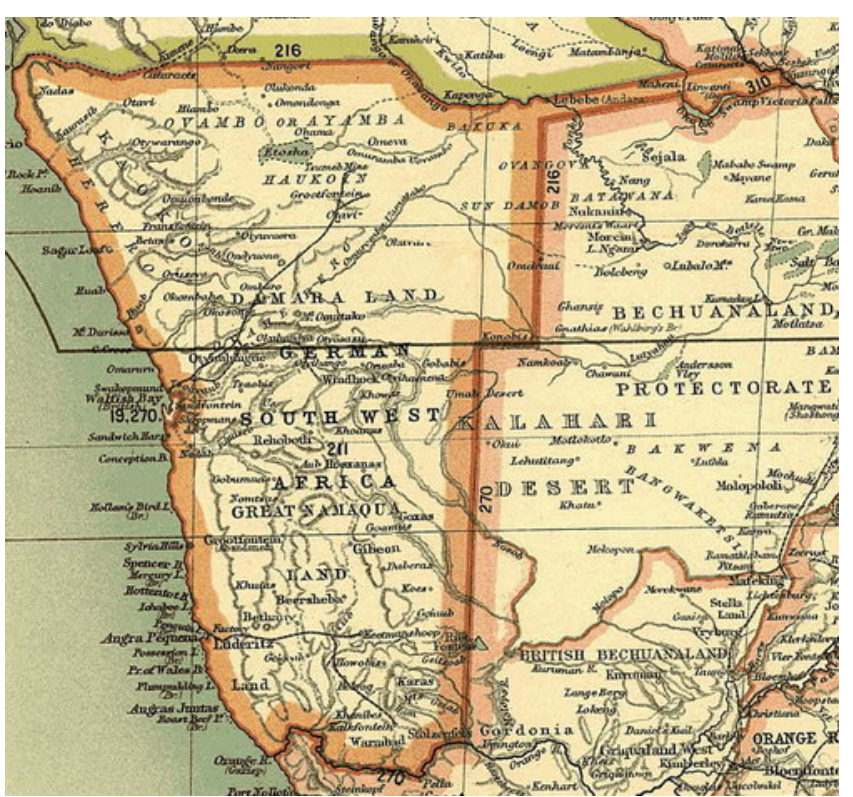

Fuente: Gallery Ezakwantu, en Diario El País (2012)

\footnotetext{
${ }^{4}$ En la bibliografía consultada, el pueblo nama se lo designa indistintamente como namaqua.
} 
Además de los asesinatos, otras prácticas genocidas como envenenamiento de cisternas de agua, trabajos forzados, esclavitud de sobrevivientes, mujeres tomadas para servir a los colonizadores, redujeron la población. "Se calcula de una población de 80.000 hereros, el $80 \%$ fue exterminado. Igual suerte corrió la comunidad Namaqua, que sufrió la pérdida de la mitad de sus 20.000 miembros" (Ceamanos, 2016, p.96). Alemania Imperial y las empresas ejecutoras de la ocupación del territorio, a través de los emprendimientos comerciales pusieron en práctica el exterminio y la destrucción de la cultura tribal y la organización social de los pueblos nativos. Además se realizaron experimentos médicos con miembros de las tribus. Los que sobrevivieron a los trabajos forzosos y a los campos de concentración emprendieron la búsqueda de la reparación.

En la Figura 4 se puede observar una vista panorámica de un campo de concentración, en el edificio del fondo de la imagen está la bandera alemana flameando. Según Erichsen (2005), en el mes de agosto de 1906 había 5.183 prisioneros en el Campo de Windhoek, y en el mismo año, en abril se registraban 7000. Gran parte de estos prisioneros constituyeron una población efímera que era trasladada a otros campos o trasladados para realizar trabajo forzoso en la construcción de vías de ferrocarril o en las minas.

FIGURA 4. Campo de Windhoek

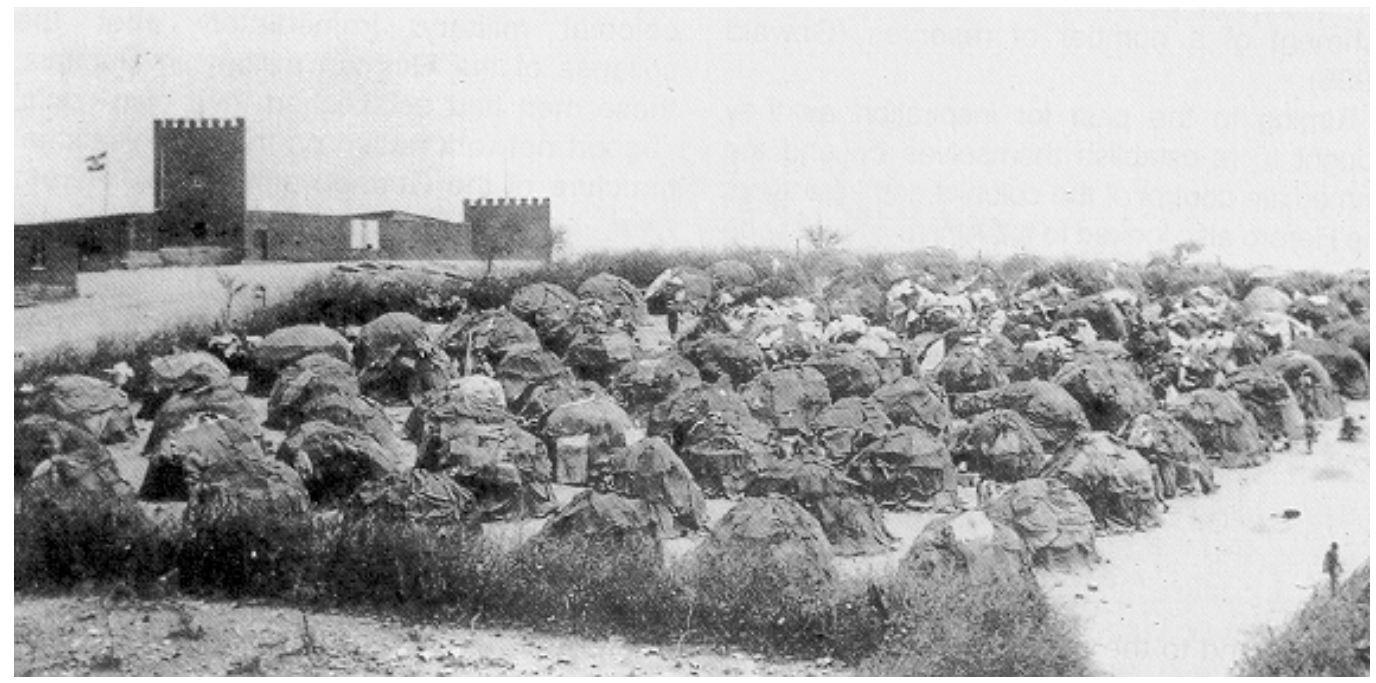

Fuente: Erichsen, 2005, p. 43

Según Bruneteau (2009), en el caso de los Herero se puede observar una política preparatoria de exclusión jurídica y económica. Desde el comienzo de la ocupación de este territorio en el sudoeste de África se practicó una política de discriminación y segregación racial que resultó en el confinamiento de poblaciones de herero en áreas tribales. Estaban exceptuados de las garantías de derecho colonial alemán, éstas solo eran para los colonos alemanes. "De hecho, hacían falta siete testimonios africanos para igualar al de un blanco, lo que legitimaba todos los abusos y actos criminales" (Bruneteau, 2009, p. 46).

El racismo científico que primaba en esta época también tuvo su experimentación en territorio de los hereros. Al igual que en otros lugares, con el propósito de investigar y demostrar la supuesta inferioridad racial de los nativos africanos o las diferencias entre las distintas etnias, se realizaban estudios y experimentos. Para ello se apoderaron de restos humanos (Figura 5) para su estudio y experimentación en institutos alemanes.

Este genocidio está considerado como un precedente de los crímenes nazis. Algunos de sus protagonistas coinciden. Franz Ritter von Epp participó en la represión de los herero y fue también un importante miembro del partido nazi. Eugen Fischer, uno de los teóricos nazis, desembarcó en África del Sudoeste Alemana para realizar una investigación que demostrara la inferioridad racial 
de los africanos. Fischer, cuya obra influyó en la redacción de Mein Kampf (Hitler 1925), fue presidente del Kaiser Wilhelm Institute of Anthropology, Human Heredety, and Eugenics y apoyó investigaciones como la del criminal nazi Josef Mengele. Para llevar a cabo los experimentos, centenares de ojos, cráneos, penes y otras partes del cuerpo humano de víctimas africanas fueron enviados a Alemania (Ceamanos, 2016, p. 138-139).

En la actualidad "hay cerca de 5500 calaveras y huesos de la colección Von Luschan. Hoy se encuentran en manos de la Fundación Patrimonio Cultural Prusiano" (Pelz, 15 de abril de 2018). Von Luschan se desempeñó como asistente de dirección en el Museo de Etnología en Berlín, en 1885 comenzó una campaña de recolección. Tal como lo hicieron otros científicos de esa época, la intención era investigación. De este modo arribaban desde los territorios coloniales restos humanos, "Misioneros y funcionarios enviaron restos a las instituciones de investigación alemanas, a menudo sin un objetivo específico. Los soldados coloniales enviaban las cabezas de los colonizados para ser estudiadas en el entonces Imperio Alemán" (Pelz, 2018). Se cometió genocidio, tal como lo expresa "la experta del Museo de Etnología de Colonia, Larissa Förster: "Fue claramente una orden para eliminar a gente perteneciente a un grupo étnico específico y sólo porque formaban parte de este grupo”. (Moreno Alcojor, 2012, s/p).

FIGURA 5. Traslado de cráneos desde Namibia y exposición en Alemania
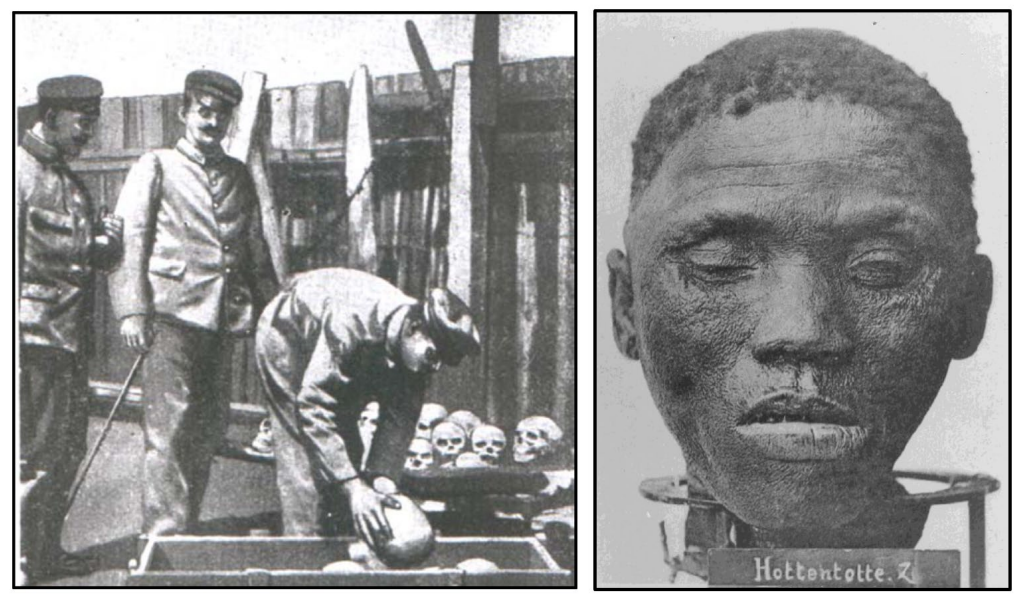

Fuente: Erichsen, 2005

Entre 1904 y 1908 se organizó un campo de exterminio en Shark Island en el que se realizaban experimentos pseucientíficos con los prisioneros por este motivo se la denomina Isla de la Muerte. Con una longitud de 1200 metros de largo y 300 de ancho, esta isla fue conectada al continente por un puente. Existía un poblado, Luderitz, que funcionaba como factoría pesquera, en torno al cual luego se creó el campo de concentración al que llevaban los prisioneros. En Europa no todos estaban de acuerdo con el proceder del ejército alemán en África, es así que se destinaron fondos y personal para la elaboración de investigaciones e informes respecto del accionar de los enviados a las colonias. Estos datos publicados en lo que se conoció como el "Blue Book" o Libro Azul ${ }^{5}$ (Figura $N^{\circ}$ 6), provocaron polémica en la vida política de Alemania.

En el contexto de la Primera Guerra Mundial, un oficial Británico, Thomas O”Reily, escribió el informe con los testimonios de las atrocidades acaecidas en territorio africano. El Parlamento británico elaboró un texto en 1918 denominado "Reporte de los nativos del sudoeste de África y su trato por los Alemanes pero “(...) este quedó en el olvido cuando los británicos decidieron no difundir

\footnotetext{
${ }^{5}$ Élise Fontenaille-N'Diaye en 2015 publica una novela titulada "Blue Book", editada por Calmann Levy, en la cual se recupera la memoria de las atrocidades padecidas por Hereros y Namas. Se pueden consultar comentarios en : $\underline{\text { https://la- }}$ plume-francophone.com/2015/03/15/blue-book-elise-fontenaille-ndiaye/
} 
esta información, temerosos de que, a su vez, los alemanes sacaran a la luz sus atrocidades en el continente africano" (Ceamanos, 2016, p 96).

FIGURA 6. Libro Azul publicado en 1918

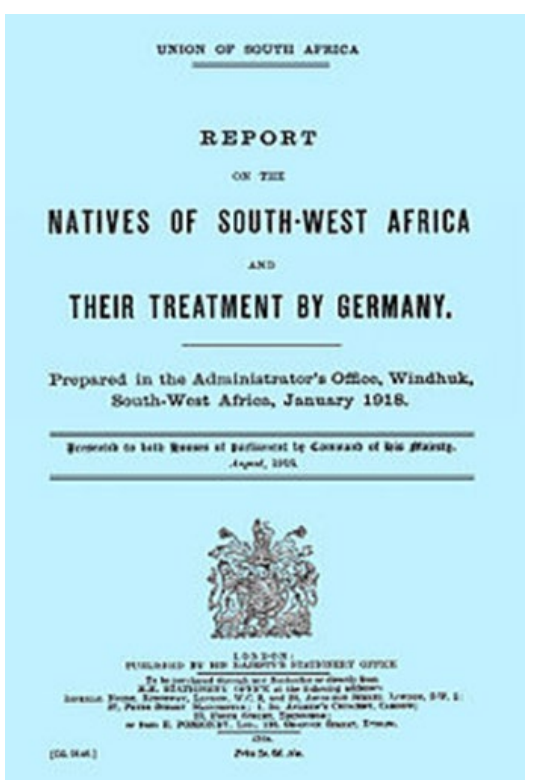

Fuente: https://www.africaye.org/el-genocidio-herero-y-nama-la-larga-espera-por-la-reparacion/

La Primera Guerra Mundial cambió la situación de Alemania en África, Gran Bretaña invadió la colonia por lo tanto al finalizar el conflicto el territorio quedó en sus manos, bajo el mandato de la Sociedad de Naciones. Esta organización encomendó la administración del territorio denominada como África Sudoccidental a la Unión Sudafricana. De este modo Namibia estuvo setenta años en manos de Sudáfrica ${ }^{6}$, ya que luego de la Segunda Guerra Mundial el gobierno de Sudáfrica se negó a devolver el mandato de este territorio a la sucesora de la Sociedad de Naciones, la Organización de Naciones Unidas (ONU).

El problema de Namibia se vinculaba con la confrontación Este-Oeste. La Guerra Fría influyó en este territorio africano provocando la independencia tardía de Namibia. "Los rasgos distintivos de la Guerra Fría eran el abuso de poder, el recurso a la violencia, el fracaso en la construcción de estados eficientes, así como la disposición de las democracias occidentales a consentir la destrucción y la dilapidación de las riquezas materiales y culturales africanas" (Huband, 2004, p.17). La distensión entre la URSS y EE UU permitieron una solución conjunta al proceso de independencia que se materializó con la celebración de elecciones libres, controladas por la ONU, en noviembre de 1989.

\subsection{Las reivindicaciones de reparación histórica actuales}

Gewald (2003) sostiene que el nazismo cambió la importancia y el significado del genocidio en Namibia. Existen vínculos entre las prácticas criminales que se experimentaron en África y las que con posterioridad se aplicaron en la Alemania nazi, es decir que se pueden encontrar vínculos de causalidad entre el colonialismo en África y el auge del nacional socialismo a mediados del siglo XX. El reclamo actual de los hereros se basa en estos vínculos para justificar sus reclamos y luchar por el reconocimiento del genocidio por parte del gobierno alemán. Desde el fin de la Segunda Guerra

\footnotetext{
${ }^{6}$ Sudáfrica mantuvo la ocupación del territorio a través de campañas militares para frenar las acciones del Ejército de Liberación Popular de Namibia en su lucha por la independencia. En diciembre de 1988, la mediación de Estados Unidos, Sudáfrica, Angola y Cuba logró un acuerdo que determinó la salida del ejército sudafricano de Namibia y, a la vez, el retiro paulatino de los 50 mil soldados cubanos presentes en Angola. La SWAPO ganó con el 60\% del electorado, Sam Nujoma se proclamó como primer presidente de Namibia independiente a partir del 21 de marzo de 1990.
} 
Mundial y el surgimiento de los estudios sobre genocidios, la lucha de los Herero ha sido lento pero sostenido. Diferentes actores políticos como los partidos nacionalistas SWANU y SWAPO (Organización Popular del África Sudoccidental), grupos de exiliados anticoloniales, entre otros, han apoyan la lucha por el reconocimiento del genocidio ocurrido en Namibia.

En el año 2001 con el propósito de reivindicar reparaciones a los daños sufridos durante el período colonial, se presentan acciones en Estados Unidos, por la Corporación de Reparaciones al Pueblo y a la tribu Herero.

Los hereros iniciaron un proceso contra el Deutsche Bank, alegando que era la principal entidad financiera y bancaria en el dominio alemán del sudoeste africano. Se alegó que Gesellschaft, adquirida por el Deutsche Bank en 1929, había controlado junto con el Deutsche Bank prácticamente todas las operaciones financieras y bancarias en dicho territorio, entre 1890 y 1915 (Sarkin, 2004, p 97).

Las acusaciones se basan en los argumentos que demuestran que estas corporaciones financieras tuvieron una participación directa a través el apoyo económico al gobierno alemán y compañías privadas en los emprendimientos comerciales coloniales y por lo tanto, en los crímenes cometidos contra los Hereros y los Nama. La compañía responsable de construir redes ferroviarias en el territorio también fue acusada por obtener ventajas económicas del trabajo esclavo.

Posteriormente, se iniciaron acciones legales contra el gobierno alemán, en este sentido el jefe de los Hereros Kuaima Isaac Riruako (1935-2014) encabezó la lucha política y judicial por la reivindicación de los crímenes de lesa humanidad en contra de su pueblo. En los reclamos manifestó, "Estoy procesando gobiernos legítimos y compañías que operaban en la época colonial. (...) somos semejantes a los judíos que fueron destruidos. Los alemanes pagaron por la sangre de los judíos. Compénsennos también. Es el momento de curar la herida" (Sarkin, 2004, p. 98). El gobierno alemán no accedió a pagar compensaciones por el genocidio y el gobierno de Namibia no apoyó el reclamo de los hereros con el argumento que solo se buscaba resarcimiento para los hablantes de idioma herero y no para todos los namibianos.

En enero de 2004, Alemania pidió por primera vez perdón por las muertes ocasionadas a los herero durante la ocupación colonial, pero negó cualquier compensación económica. Luego, en agosto del mismo año, Berlín realizó una disculpa por el «genocidio de 1904» en Okakarara (región ubicada al este de Namibia). Durante la ceremonia de conmemoración de los 100 años de la masacre, la ministra alemana de Desarrollo, Heidemarie Wieczorek-Zeul, señaló: "aceptamos nuestra responsabilidad moral e histórica y la culpabilidad de los alemanes de entonces. Yo presento mis respetos ante vuestros ancestros masacrados. En el nombre de Dios os pido vuestro perdón" (Villapadierna, 2004, s/p).

Entre los años 2011 y 2014 el gobierno alemán accedió a devolver restos de seres humanos. En 2018 se concretó la tercera entrega, pero solo estos gestos de reconciliación no son suficientes para el pueblo herero que reclama y exige disculpas oficiales y reparaciones económicas. En la imagen (Figura 7) se puede apreciar un vehículo a las afueras del aeropuerto que manifiesta "Alemania debe pagar. Genocidio Herero-Nama” en el momento que arriban restos de cráneos devueltos por Alemania a Namibia en 2011.

La devolución de algunos de los restos saqueados en la época de la colonización no es suficiente para reparar los daños causados (Figura 8). Si bien Alemania niega las reparaciones económicas, el grupo herero que reclama pretende que la reparación económica gire en torno a la recuperación y posibilidad de acceso a las tierras que les fueron arrebatadas. 
FIGURA 7. Reclamos de reconocimiento

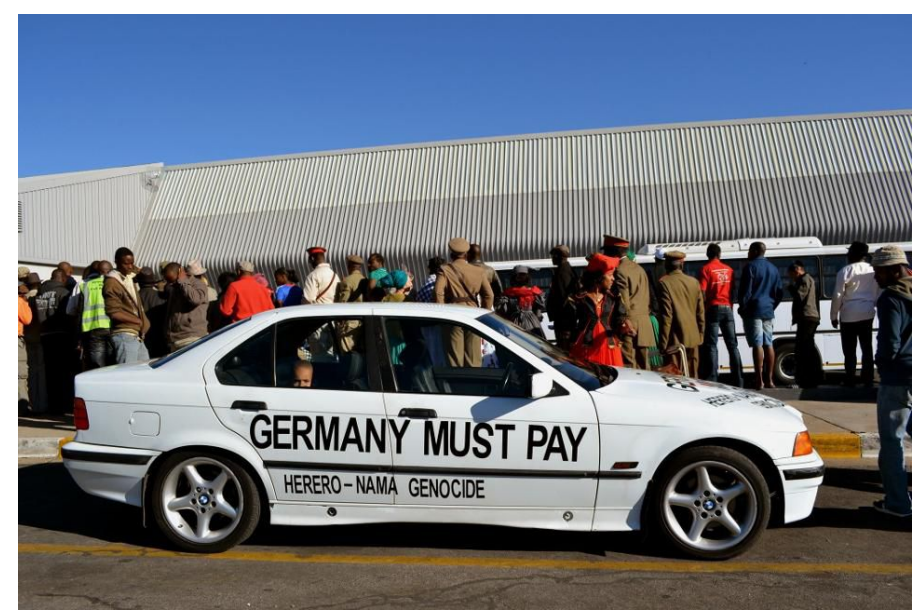

Fuente: Ochab, 2018.

FIGURA 8. Entrega de cráneos realizada en Alemania

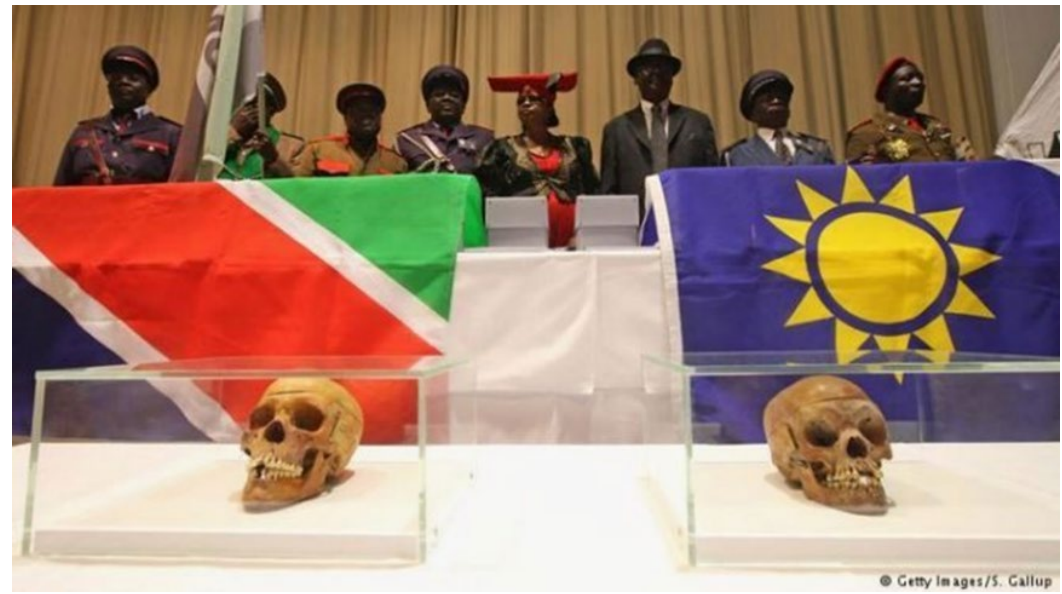

Fuente: Valdehíta, 2017.

En marzo de 2017, en el Memorial del Holocausto en Paris ${ }^{7}$ se realizó una exposición de archivos, fotografías, dibujos, proyecciones y conferencias sobre el genocidio en Namibia, episodio de la historia desconocido para la mayoría de los europeos.

Antes del regreso de las calaveras en el año 2011, el gobierno de Namibia había designado un lugar próximo a unos pocos kilómetros al sur de Windhoek, como el sitio de entierro apropiado para los restos del genocidio. Sin embargo, los representantes de las víctimas de los Herero piensan que la evidencia no debería ser enterrada. Los jefes del Consejo Herero y representantes de los Namas solicitaron al gobierno que los cráneos se mantengan de manera profesional para sostener viva la memoria de esta parte de la historia de Namibia para las generaciones futuras (Amukwaya Shigwedha, 2016). Surge así una disputa entre las intenciones gubernamentales y los reclamos de las comunidades directamente afectadas, por un lado la posibilidad de exhibir los cráneos en un museo

\footnotetext{
7 En la página web del Memorial del Holocausto de París (http://www.memorialdelashoah.org/archives-etdocumentation/genocides-xx-siecle/genocide-herero-nama.html) se puede encontrar un archivo con textos explicativos e imágenes que ilustran el análisis histórico. En ese link se puede acceder a otro (http://genocide-hereronama.memorialdelashoah.org/ressources.html) "El primer genocidio del siglo XX" que tiene recursos tales como libros u otros archivos con información sobre el Genocidio Herero y Nama. Un video síntesis titulado "Paris arroja luz sobre el primer genocidio del siglo XX, el de Namibia" se puede visualizar en: https:/www.youtube.com/watch?v=ykCljJGtMYo. Publicado el 25 de noviembre de 2016.
} 
y por otro, el respeto a las tradiciones culturales de las comunidades. Asimismo, el dilema del regreso de los restos debería estar acompañado de la aceptación, reparación y disculpas por parte de los perpetradores ${ }^{8}$.

En julio de 2019, ciento quince años después de las matanzas en Namibia, el presidente de la Cámara Alta del Parlamento de Alemania, Daniel Gunther, reconoció el Genocidio. Por su parte el Ministro de Cooperación y Desarrollo alemán Gerd Mueller (Figura 9) manifestó el reconocimiento de crímenes cometidos entre 1904 y 1908 como genocidio y negocia las reparaciones correspondientes. Las víctimas de las masacres recibirán indemnizaciones y se negocia con el gobierno de Namibia reparaciones con programas de ayuda al desarrollo (Rojas, 2019).

FIGURA 9. Ministro Alemán reconoce el Genocidio de Hereros y Namas

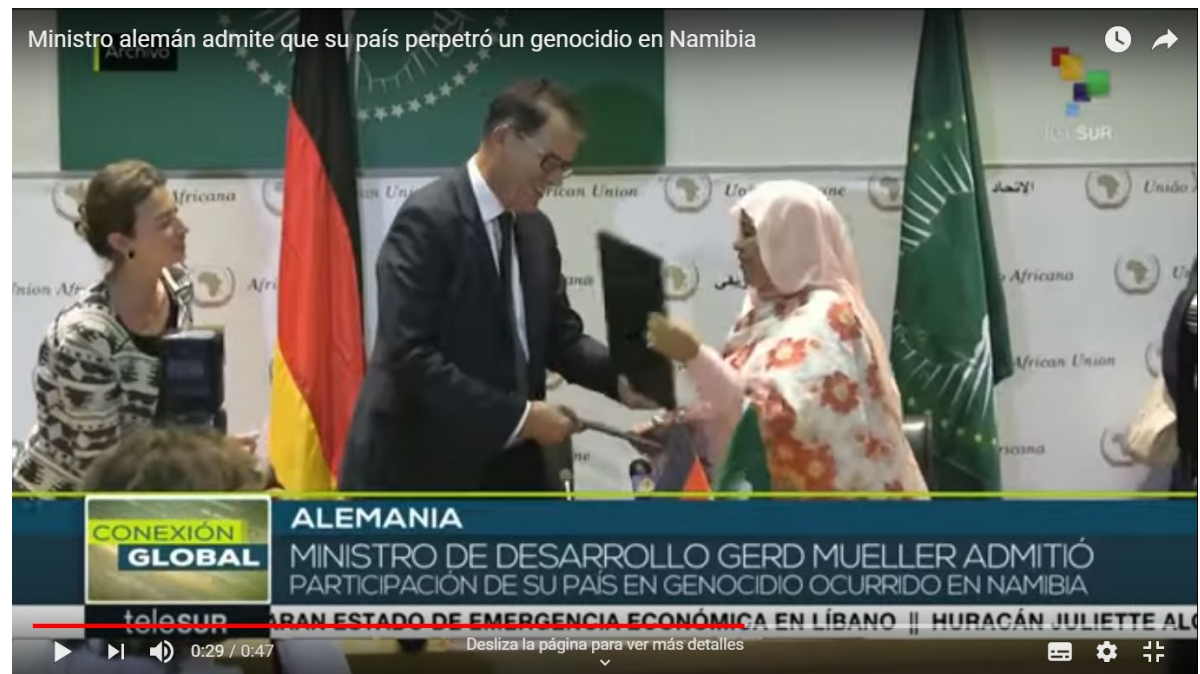

Fuente: https://www.youtube.com/watch?v=4MiZZux7fa4 Telesur TV 3/9/19

El regreso de cráneos y esqueletos de Alemania debería ser acompañada de aceptación, reparación y disculpa por parte del perpetrador. Sin embargo, la cuestión de si la disculpa y la compensación pueden remediar injusticias pasadas genera otros debates. Como resultado, cualquiera que sea la política que rodea estos huesos, la rendición de cuentas y la justicia por el genocidio deben ser ponderadas como los factores clave para tratar de abordar el dolor y el sufrimiento de las víctimas. (Amukwaya Shigwedha, 2016). Entre las alternativas propuestas en las negociaciones para pagar el precio de las reparaciones se encuentran los programas de ayuda al desarrollo (Rojas, 2019). En junio de 2021 Alemania rechazó las exigencias de indemnizaciones realizadas por sectores en Namibia. Al reconocimiento oficial del genocidio se sumaron la creación de un fondo de ayuda económica destinado a proyectos de desarrollo durante treinta años. Sin embargo representantes Herero y Nama no acuerdan con las negociaciones (DW Noticias, 09.06.2021).

En el año 2007, con el propósito de recordar a las víctimas hereros y namaquas que murieron en el campo de concentración de Swakopmund, se creó el Memorial del Campo de Concentración de Swakopmund. El Memorial (Figura 10) es una lápida situada en el cementerio africano de la ciudad del mismo nombre. En dicho lugar estaba ubicado un cementerio informal de las víctimas del campo de concentración que funcionó en esta área. Según se expresa en el sitio de UNESCO "Memorias Situadas" (2021),

\footnotetext{
${ }^{8}$ En el Informe "Los campos de concentración alemanes en África" elaborado por Foro Global y publicado el 22 de marzo de 2017, se pueden apreciar una evolución del reclamo de Hereros y Namas a Alemania, documentos históricos tales como imágenes, videos $y$ testimonios de los descendientes. Recuperado de: https://www.youtube.com/watch?v=R8NG66isOCA
} 
Todos los años a partir de 2007, a fines de marzo se organiza el Swakopmund reparation walk (Marcha de la reparación de Swakopmund). Participan centenares de personas de las comunidades herero y namaqua para conmemorar a las víctimas del poder colonial alemán entre 1904 y 1908 en la actual Namibia y exigir reparaciones al Estado alemán. En el marco de la Marcha, se organizan discursos, ceremonias religiosas y otras actividades culturales. La Marcha finaliza frente al Memorial del Campo de Concentración de Swakopmund.

FiguRA 10. Memorial del Campo de Concentración de Swakopmund

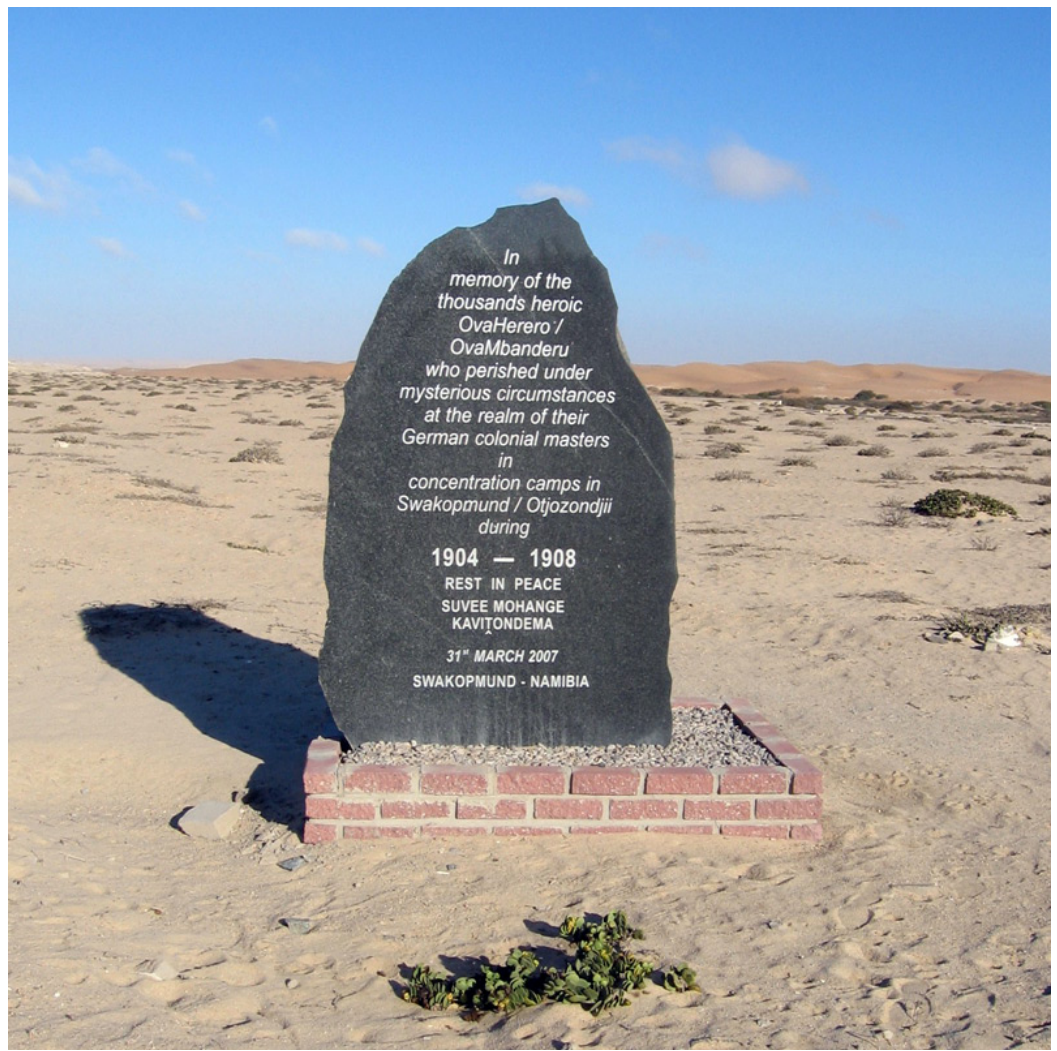

Fuente: https://www.cipdh.gob.ar/memorias-situadas/lugar-de-emoria/memorial-del-campo-de-concentracionde-swakopmund/

Por otra parte otros actores sociales, tales como Asociaciones civiles, Instituciones educativas, maestros se movilizan para incorporar en la enseñanza las temáticas vinculadas con el pasado colonial de países europeos y en este caso particular del genocidio en Namibia. Por un lado en Alemania, la Asociación Gemeinsam für Afrika (Juntos por África) promueve la elaboración de materiales educativos que incluyen el debate acerca del rol de Alemania en el genocidio (DW, 2020). Maestros, profesores, artistas y activistas se involucran en la investigación y la incorporación de esta temática destinadas a estudiantes como a la ciudadanía en general. Por otra parte, en Namibia, en la Asociación de Museos de este este país, se creó "un proyecto cuyo objetivo es promover la enseñanza del Holocausto y otros genocidios en Namibia, que incluye la primera exposición sobre el genocidio de 1904 contra los Hereros y los Namas, que se presentará en las 14 regiones del país" (UNESCO, 2018). La exposición se titula: "El genocidio namibio - Sacar provecho de las lecciones del pasado", a partir del cual se pretende incorporar la enseñanza del genocidio en Namibia, temática ausente en el sistema educativo de este país. Una de las autoras del Proyecto expresa los principales propósitos que pretenden alcanzar,

Nuestro proyecto y nuestra exposición se titulan "Learning from the past" (Sacar provecho de las lecciones del pasado) y es esto lo que esperamos lograr. Tratamos de utilizar la enseñanza de la 
historia como plataforma para enseñar la sensibilidad y la tolerancia en el seno de la comunidad namibia. Y no sólo la tolerancia con respecto a la raza, sino también sobre otras cuestiones sujetas a debate en nuestras comunidades, tales como la violencia basada en cuestiones de género, el sexismo, la homofobia y toda forma de "ismo" o de fobia. Tratamos de sanar una comunidad que se encuentra muy dividida sobre las cuestiones religiosas y tradicionales. Es por ello que tratamos de construir una comunidad que se perciba como un todo, antes que dividida en "nosotros contra ellos"; una comunidad que comprenda la belleza de la diversidad en lugar de exacerbar las diferencias. Tratamos de construir una comunidad multicultural, en la que cada cual desempeñe un papel. En este contexto, hablar de enseñar "la tolerancia" es incluso poco, ya que se trata de enseñar a apreciar al otro por su diferencia y a querer sus diferencias antes que convertirlas en objeto de miedo o de odio (UNESCO; 2018, s/p).

Las decisiones y acciones que desarrollan actores del ámbito educativo y cultural, es decir con la incorporación de la discusión del pasado colonial y genocidio sufrido por uno de los pueblos que habitan Namibia, los convierten actores políticos que contribuyen a construir un nuevo curriculum que contempla la recuperación de la memoria colectiva.

\section{DISCUSIÓN}

En este trabajo se exploró el proceso que afectó a los Hereros y Namas en Namibia, a principios del siglo XX. La expansión colonial del siglo XIX, época en que los imperios toman posesión de territorios en África, Asia y algunas porciones de América fue el principio de la construcción social de los territorios con desiguales relaciones de poder y materialización de violencias, muchas de las cuales se consideran procesos genocidas.

El recorrido histórico desarrollado posibilita pensar en perspectiva geohistórica la realidad actual de los vínculos entre Namibia y Alemania atravesados por los reclamos de reparación histórica por el genocidio perpetrado por el Imperio Alemán. Asimismo las acciones emprendidas tanto a nivel internacional como interno permiten consolidar el proceso de construcción de memoria colectiva, esencial para la debida reparación y la no repetición de prácticas violentas. La verdad, la justicia y la reparación son pilares para el cumplimiento de los derechos humanos en el marco de la Justicia Transicional, sin embargo Salvioli, Relator Especial de Naciones Unidas para la promoción de la verdad, la justicia, las reparaciones y las garantías de no repetición, (desde 2018 a la actualidad) expresa lo siguiente,

Los tres forman parte de una misma cuestión: el cumplimiento de los estándares en materia de Derechos Humanos, yo agrego lo relativo a las garantías de no repetición y el componente de memoria, que creo que es el quinto pilar de la justicia transicional y así lo hice saber en mi último informe al Consejo de Derechos Humanos. Las experiencias muestran que cuando uno de estos componentes falla, el proceso no es exitoso y los problemas subsisten (Salvioli en Beltrán, 2020, p. 113).

Del análisis de los documentos consultados se interpreta que en el presente es posible reconstruir el pasado a partir de las múltiples versiones del mismo. Aguilar (1996, p. 42) expresa que "(...) la memoria no recuerda las cosas tal y como fueron, sino que es una reconstrucción del pasado desde el presente que modula, recrea, olvida e interpreta, de diversos modos el pasado". Entonces, existe una memoria hegemónica que se articula con las tradiciones y memorias del país, que influye sobre las múltiples memorias populares, es decir hay usos políticos del pasado. En la actualidad estas miradas hegemónicas se ven interpeladas debido a la recuperación de los testimonios de sobrevivientes y descendientes que se identifican con sus experiencias y las de sus antepasados. Las conmemoraciones, rituales y homenajes que materializan conforman un parte fundamental en el proceso de transmisión para que las sucesivas generaciones la hagan propia. 
La noción de memoria presenta dos dimensiones. Por un lado, constituye un conjunto de recuerdos, representaciones y discursos que pueden ser individuales o colectivos que se elaboran y circulan como producto de las interacciones de los sujetos y la sociedad. Por otro lado, las creencias, ritos, normas que hacen a la identidad y al destino de un grupo que se construyen para recuperar las identidades avasalladas y silenciadas por regímenes de exterminio (Levín, 2013). La memoria se ha constituido en un asunto crucial de esta época vinculada con las experiencias trágicas y traumáticas de masacres y genocidios acontecidas en el siglo XX.

El abordaje de problemas sociales relevantes o temas controvertidos posibilita relacionar los saberes a enseñar con la realidad, estimula la formación de conciencia crítica, de opiniones del respeto por opiniones diversas. Asimismo promueve la participación y el compromiso con temas comprometidos con la defensa de la cultura democrática (Santisteban, 2019). Por otra parte, esta metodología de enseñanza genera controversias debido a que existen diversas alternativas en la búsqueda de soluciones y diferentes enfoques o perspectivas que las sustentan, promueve el debate y la búsqueda de argumentos. En síntesis, contribuye a la formación del pensamiento crítico, despierta interés en indagar y establecer comparaciones con temáticas relevantes en diferentes escalas geográficas.

\section{REFLEXIONES}

El camino político en la lucha para el resarcimiento de las víctimas es reciente. Las acciones que lleven a cabo los actores internos, los gobiernos de Namibia y Alemania, y organizaciones internacionales tanto políticas como académicas, construirán en el futuro la reparación por los derechos humanos de los pueblos afectados. El caso explicado en el presente artículo se visibilizó en los periódicos internacionales en el año 2017, si bien investigadores de diferentes países trabajan desde hace años en el tema, decisiones como el Museo del Holocausto de París de preparar una muestra especial para dar a conocer fuentes fotográficas, fílmicas y documentales del genocidio de los Hereros y Namas puso en tensión los reclamos ante la comunidad internacional.

La toma de conciencia de actores internos de Namibia tales como educadores, descendientes de los pueblos masacrados contribuye a enriquecer el debate a escala regional e internacional. Se considera que la memoria es una construcción colectiva a partir de los recuerdos y representaciones de sujetos que experimentan procesos traumáticos. Además contribuye a la materialización de los cinco pilares de la justicia transicional mencionados, la verdad, la justicia, la reparación, las garantías de no repetición y la memoria. De la presencia de todos ellos y su articulación depende que en el futuro se construyan sociedades y territorios con convivencia pacífica. La investigación y enseñanza del caso presentado requiere de un enfoque en perspectiva geo-histórica en el que el proceso de colonización es clave para comprender las relaciones asimétricas de poder entre los pueblos dominados y los imperialistas. De modo que, a partir del debate de contextos presentes se logre hilvanar con el pasado de los territorios y se transversalicen cuestiones políticas, legales, económicas, ambientales, demográficas y culturales.

Es por ello que la Geografía, a través de investigadores y profesores que miren la realidad desde la perspectiva de los derechos humanos, tiene la responsabilidad y el compromiso de investigar y enseñar este tipo de experiencias para promover el conocimiento y en consecuencia crear conciencia del rol activo que tienen todos los sujetos que integran la sociedad. Es tarea de los investigadores continuar con publicaciones académicas que permitan a los profesores disponer de materiales para seleccionar y organizar la enseñanza de este genocidio poco conocido y escasamente investigado. El presente escrito pretende instalar el debate acerca de la temática, cada docente de acuerdo al contexto educativo, a los proyectos de enseñanza que planifique decidirá las estrategias pertinentes y adecuadas a su grupo clase. Por otra parte la comparación con realidades locales o regionales del pasado y del presente otorga la complejidad de variables que se entrelazan para el funcionamiento de las relaciones que se plasman en los territorios. Las controversias y disputas discursivas y normativas 
contribuyen a debatir, analizar y comprender la Geografía contemporánea desde múltiples perspectivas.

\section{Referencias}

Aguilar, P. (1996). Memoria y olvido de la Guerra Civil Española. Madrid: Alianza Editorial. Albet, A y Benejam, P. (2000). Una Geografía Humana renovada: Lugares y Regiones en un mundo Global. Barcelona: Vinces Vives

Amukwaya Shigwedha, V. (2016). The return of Herero and Nama bones from Germany: the victims' struggle for recognition and recurring genocide memories in Namibia. En J.M. Dreyfus y E. Anstett (Eds.), Human remains in society Curation and exhibition in the aftermath of genocide and mass-violence (pp. 197-219). Manchester: Manchester University Press.

Aracil, R., Oliver, J. y Segura, A. (1995). El mundo actual. De la Segunda Guerra Mundial a nuestros días. Barcelona: Universidad de Barcelona.

Beltrán, E. (2020). Entrevista a Fabián Salvioli. La justicia internacional: el poder de la gente en todo el mundo. Revista Electrónica de Derecho Internacional Contemporáneo, 3(3), 112-120. DOI: $10.24215 / 2618303 \mathrm{Xe} 006$.

Bruneteau, B. (2009). El siglo de los genocidios. Madrid: Alianza Editorial.

Ceamanos, R. (2016). El Reparto de África. De la Conferencia de Berlín a los conflictos actuales. Madrid: Casa África.

Declaración Universal de los Derechos Humanos. (1948). Recuperado de: https://www.ohchr.org/en/udhr/documents/udhr_translations/spn.pdf

Duverger, M. (1981). Métodos de las Ciencias Sociales. Barcelona: Ariel: Geografía.

DW Noticias (2021, junio 4). Los herero quieren negociar reparaciones. Recuperado de https://www.dw.com/es/los-herero-quieren-negociar-reparaciones/av-57784593

DW Noticias (2021, mayo 28). Alemania reconoce como "genocidio" las matanzas cometidas en Namibia. Recuperado de https://www.dw.com/es/alemania-reconoce-como-genocidio-lasmatanzas-cometidas-en-namibia/av-57709147

DW Noticias (2021, junio 9). Alemania rechaza indemnizar a namibios tras reconocer genocidio. Recuperado de https://www.dw.com/es/alemania-rechaza-indemnizar-a-namibios-trasreconocer-genocidio/a-57833227

DW (2017, octubre 7). Cuestión de fe - Los herederos de Lutero en Namibia - Misión y genocidio. Recuperado de https://www.dw.com/es/alemania-y-el-genocidio-de-los-herero-el-no-a-lasreparaciones-econ $\% \mathrm{C} 3 \% \mathrm{~B} 3$ micas-contin $\% \mathrm{C} 3 \% \mathrm{BAa} / \mathrm{a}-44884965$

DW (2020, octubre 11). Cómo las escuelas alemanas ignoran la historia colonial del país. Recuperado de https://www.dw.com/es/c\%C3\%B3mo-las-escuelas-alemanas-ignoran-la-historia-colonialdel-pa\%C3\%ADs/a-55231905

Erichsen, C, W. (2005). "The angel of death has descended violently among them": concentration camps and prisoners-of-war in Namibia, 1904-08. Leiden: African Studies Centre.

Feierstein, D. (2016). Introducción a los Estudios sobre Genocidio. Buenos Aires: EDUNTREF.

Gallery Ezakwantu. (2012). Diario El Pais: Recuperado de https://elpais.com/elpais/2012/05/04/africa_no_es_un_pais/1336134156_133613.html

Garibian, S., Anstett, E. y Dreyfus, J.M. (Dirs.) (2017). Restos humanos e identificación. Violencia de masa, genocidio y el "giro forense". Buenos Aires: Miño y Dávila.

Gemeinsam für Afrika (s/f). Asociación Juntos por África. Recuperado de https://www.gemeinsamfuer-afrika.de

Gewald, J. B. (2003). Herero genocide in the twentieth century: politics and memory. En J, Abbink, K. Walraven y M. Bruijn (Eds.), Rethinking resistance: revolt and violence in African history. 
Hérin, R. (2006). Por una geografía social, crítica y comprometida. Scripta Nova. Revista electrónica de geografía y ciencias sociales, 218(93). Recuperado de: http://www.ub.es/geocrit/sn/sn-21893.htm

Huband, M. (2004). África después de la Guerra Fría. La promesa rota de un continente. Barcelona: Paidós.

Kabunda Badi, M. (2016). De la Conferencia de Berlín al acaparamiento de tierras. O de la Primera a la segunda Colonización de África. En R. Ceamanos, El Reparto de África. De la Conferencia de Berlín a los conflictos actuales (pp. 7-17). Madrid: Casa África.

Lemkin, R. (1946). Genocide. American Scholar, 15(2), 227-230.

Levín, F. (2013). El pasado reciente en la escuela, entre los dilemas de la historia y la memoria. En I. Siede (2013). Ciudadanía para armar. Aportes para la formación ética y política (pp.157-178) Buenos Aires: AIQUE.

Litwin, E. (2008). El oficio de Enseñar. Condiciones y contextos. Buenos Aires: Paidós.

Martins, A. (2017). Por qué Alemania no se disculpó aún por "el primer genocidio del siglo XX" en una de sus colonias en África. Recuperado de https://www.bbc.com/mundo/noticiasinternacional-38533627

Moreno Alcojor, A. (2012) Namibia, ¿primer genocidio del siglo XX? Diario El País. Recuperado de https://elpais.com/elpais/2012/05/04/africa_no_es_un_pais/1336134156_133613.html.

Murias, C. (2017). ¿Compensará Alemania a las víctimas del "ler genocidio del s. XX? El genocidio herero y nama, la larga espera por la reparación. Disponible en Recuperado de https://www.africaye.org/el-genocidio-herero-y-nama-la-larga-espera-por-la-reparacion/

Namib Times (2017). Ovaherero and Nama Community feels they should be included in reparation talks. Recuperado de https:/www.namibtimes.net/ovaherero-and-nama-community-feelsthey-should-be-included-in-reparations-talks/

Nin, M. C. (2020). Genocidio, concepto invisibilizado en los libros de textos de geografía. GEOGRAPHICALIA, 72, 65-86. DOI: 10.26754/ojs_geoph/geoph.2020724594

Ochab, E. (2018). The Herero-Nama Genocide: The Story Of A Recognized Crime, Apologies Issued And Silence Ever Since. Forbes. Recuperado de https://www.forbes.com/sites/ewelinaochab/2018/05/24/the-herero-nama-genocide-the-storyof-a-recognized-crime-apologies-issued-and-silence-ever-since/\#413db596d8c2

Oslender, U. (2018). Terror y geografía: examinar múltiples espacialidades en un mundo "aterrorizado". Clepsidra. Revista interdisciplinaria de Estudios sobre Memoria, 5(9), 68-85. Recuperado de http://ppct.caicyt.gov.ar/index.php/clepsidra/article/view/OSLENDER

Pelz, D. (2018). Alemania y el genocidio de los herero: el "no" a las reparaciones económicas continúa. Recuperado de https://www.dw.com/es/alemania-y-el-genocidio-de-los-herero-elno-a-las-reparaciones-econ $\% \mathrm{C} 3 \% \mathrm{~B} 3$ micas-contin $\% \mathrm{C} 3 \% \mathrm{BAa} / \mathrm{a}-44884965$

Pelz, D. (2018). El oscuro patrimonio cultural de los museos alemanes. Recuperado de https://www.dw.com/es/el-oscuro-patrimonio-cultural-de-los-museos-alemanes/a-43397660

Prats, J. (2001). Enseñar Historia. Notas para una didáctica renovada. Mérida: Junta de Extremadura.

Rojas, A. (2019). Alemania pagará por el genocidio de Namibia, el primero del siglo XX. El Mundo. Recuperado de: https://www.elmundo.es/internacional/2019/09/14/5d7bd9a3fc6c83fc688b465d.html

Ruiz Olabuenaga, J I. (1996). Metodología de la investigación cualitativa. Bilbao: Universidad de Deusto.

Santisteban Fernández, A. (2019). La enseñanza de las Ciencias Sociales a partir de problemas sociales o temas controvertidos: estado de la cuestión y resultados de una investigación. El Futuro del Pasado, 10, 57-79. DOI: 10.14516/fdp.2019.010.001.002

Sarkin, J. (2004). La consolidación de los reclamos de reparaciones por violaciones de los Derechos Humanos cometidas en el sur. Sur. Revista Internacional de Derechos Humanos, 1, 70-135. DOI: $10.1590 / \mathrm{S} 1806-64452004000100005$ 
Sellier, J. (2005). Atlas de los pueblos de África. Barcelona: Paidós.

Sémelin, J. (2002). Violencias extremas. ¿Es posible comprender? Revista Internacional de Ciencias Sociales. 54.4(174), 429-431.

Shaw, M. (2013). ¿Qué es el genocidio? Buenos Aires: Prometeo.

UNESCO (2021). Memorias Situadas. Memorial del Campo de Concentración de Swakopmund. Recuperado de https://www.cipdh.gob.ar/memorias-situadas/lugar-de-memoria/memorial-delcampo-de-concentracion-de-swakopmund/

UNESCO (2018). Tratamos de utilizar las enseñanzas de la historia como plataforma para enseñar la tolerancia en el seno de la comunidad namibia. Recuperado de https://es.unesco.org/news/tratamos-utilizar-ensenanzas-historia-como-plataforma-ensenartolerancia-seno-comunidad-namibia

Valdehíta, C. (2017). El Genocidio alemán de los cráneos en Namibia. Diario El Mundo. Recuperado de: https://www.elmundo.es/cronica/2017/07/19/59692479268e3e805d8b45f3.html

Valles, M. (2000). Técnicas cualitativas de Investigación social. Reflexión Metodológica y Práctica profesional. Madrid: Síntesis.

Villapadierna, R. (2004). El primer ensayo de genocidio. Diario $A B C$. Recuperado de www.abc.es/hemeroteca/historico-17-08-2004/abc/Internacional/el-primer-ensayo-degenocidio_9623135223056.html

Yin, R. K. (1994). Case Study Research: Design and Methods. Thousand Oaks, CA: Sage Publications.

\section{CÓMO CITAR ESTE ARTÍCULO}

Nin, M.C. (2021). Hereros y Namas: el comienzo de los genocidios en el siglo XX. Análisis desde la perspectiva de la geografía de la memoria. Didáctica de las ciencias experimentales y sociales, 41, 19-38. DOI: 10.7203/DCES.41.21491. 